\title{
Mental Health in Primary Care: A Qualitative Analysis Based On the Views of Mexico City Nursing Staff
}

\author{
Hernández-Becerril $\mathrm{Z}^{1}$ and Berenzon-Gorn $\mathrm{S}^{2 *}$ \\ ${ }^{1}$ Postgraduate Section of Master's Degree Program in Public Mental Health, Universidad Nacional Autónoma de México. \\ ${ }_{2}^{2}$ Medical Science Researcher, Department of Epidemiological and Psychosocial Research, Ramón de la Fuente Muñiz National Institute of Psychiatry, Mexico \\ City, DF. Mexico.
}

Received: August 17, 2016; Accepted: November 1, 2016; Published: November 7, 2016

*Corresponding author: Shoshana Berenzon, Medical Science Researcher, Department of Epidemiological and Psychosocial Research, Ramón de la Fuente Muñiz National Institute of Psychiatry, Calzada México, Xochimilco No. 101, Delegación Tlalpan, Mexico City, Tel: (55) 41605168; E-mail: berenz@imp.edu. $m x$

\begin{abstract}
Since the impact of mental disorders on the quality of life is recognized as a public health problem, experts in the field believe that primary healthcare is the best level for incorporating preventive actions. In this respect, nursing plays an important role in primary care, since it is responsible for timely detection and the promotion of self-care. It has been reported, however, that some of the gaps hindering attention to mental health are due to stigma and attitudes at the moment when care is provided.

In Mexico, mental health has yet to become a key feature of the nursing curricula, and providing suitable care is neither a possible activity nor standard practice in the everyday work of primary health care centers. The following study uses a qualitative approach to explore nurses' perception of the incorporation of mental health care into primary care on the basis of their knowledge, attitudes, beliefs and functions performed at a primary care center located in Mexico City.

The results show the difficulties of incorporating mental health care, despite the fact that it is a public health problem. The lack of suitable space, knowledge of mental disorders and human resources are the main factors limiting the care of mental disorders. Nonetheless, the nurses show interest in this issue and believe that they perform certain unacknowledged functions such as "active listening and allowing patients to relieve their feelings," although they report a persistent lack of recognition of their activities, in addition to insufficient mental health training.
\end{abstract}

Keywords: Mental health; Primary care; Nursing; Perception

\section{Introduction}

The concept of mental health is described on the basis of biological, behavioral-affective, cognitive and social elements as a complex process comprising multiple factors (biological, psychological, social, environmental, cultural, etc.) that contribute to a person's optimal development and influence his or her wellbeing [1].

It is therefore considered an essential factor for the quality of life, yet despite its importance, interest in the subject only began with the epidemiological transition, the theory that explains the changing patterns of health and disease [2]. This theory drew attention to the results of global disability and prevalence rates, in which mental and behavioral disorders are the main conditions, accounting for $7.4 \%$ of the burden of disease in terms of disability-adjusted life years.

The 2010 Global Burden of Disease study reported that 700 million people suffer from a mental disorder, [3] and that by 2013, depression, together with anxiety, were among the ten leading causes of disability in almost every region in the world [4].

Although the impact of disorders on the population's quality of life has been recognized, the care gap is still extremely large. The estimated gap for any disorder is between $78.1 \%$ and $81.4 \%$ in Mexico. In addition, the focus of mental health care in Mexico remains the psychiatric hospital. There are very few psychiatric units at general hospitals, while services at the primary care level are insufficient. Furthermore, there are geographical, social and cultural barriers to accessing mental health care, and human and financial resources are also very limited [5].

Studies in Mexico City reported that more than $65 \%$ of health centers users have some form of psychological distress; the most common disorders being depression $(26.8 \%)$ and anxiety $(10.6 \%)$ [6]. Moreover, there is evidence of frequent comorbidity of mental disorders with other chronic conditions [7]. However, lack of training, poor integration of services and the low priority given to mental health care, prevent the timely recognition and treatment of mental disorders [8].

The care gap is expressed as the percentage of people who need treatment yet fail to receive it [9]. There are several examples in both developed countries and low- and middleincome countries, where it has been found that the incorporation of mental health services into primary care helps reduce this gap. It enables people to access services closer to home, which in turn facilitates attendance, monitoring and long-term management in addition to reducing stigma and discrimination [10]. 
The enormous potential of primary care lies in the fact that it is the first contact between individuals, families, the community and the health care system. However, to improve its efficiency, strategies must be tailored to the needs and characteristics of the community and include the participation of various members of the health care team, including nursing staff [11].

Despite the above mentioned factors, several barriers have been observed to incorporating nurses into the field of mental health, including low wages, few incentives, Work overload [12] devaluation of the profession [13], lack of knowledge of mental disorders, the stigma attached to mental health sufferers [14] and the absence of standardized nursing care [15].

Nonetheless, in countries such as Gambia, Cambodia and Belize, most psychiatric services are delivered by nurses due to the shortage of other professionals. Likewise, in developed countries, nurses play a key role in the diagnosis, treatment, monitoring and rehabilitation of those suffering from a mental disorder yet provide this care in conjunction with a multidisciplinary team [16].

In Latin America, it is estimated that only $2.14 \%$ of nursing personnel specialize in mental health, and that this sub-group continually faces challenges to exercising an independent, recognized profession [17]. The situation in Mexico is similar. The number of nurses trained in mental health care is 0.5 per 100,000 inhabitants, concentrated mainly in tertiary level services [18]. The incorporation of mental health care into primary care has not yet been implemented in all units since there is more than one health system [19] and in turn, the role of nursing has yet to be defined. The aim of this study was therefore to use a qualitative approach to explore nurses' perception of the incorporation of mental health care at the primary care level.

\section{Method}

A qualitative design was used, making it possible to not only record objectively verifiable facts butalso the subjective meanings people attribute to them. Thus, the respondents' accounts were used to create a picture of nursing staff's perceptions of incorporating mental health care into primary care. Information was gathered using two qualitative techniques: observation and interviews.

Participants were selected at a primary care center located in the southern part of Mexico City. The criteria used were being a nurse with various responsibilities (auxiliary, general, graduate, supervisor or head of department), with three or more years' experience. Of a total of 23 nurses, only 14 met the inclusion criteria. Six nurses were interviewed, a number determined by data saturation. This means that although more interviews are added, this fails to yield new ideas on the subject of interest [20].

As mentioned earlier, two qualitative techniques, observation and interviews, were used to compile information, with guidelines being provided for each of them. Topics included in the observation guide were location and description of the health center, nursing area and nursing staff, nurses' functions and the places where they perform their work on a daily basis.
Observations were recorded in field notes and included a sketch of the place visited and the researcher's perceptions [21].

To conduct interviews, the guide included the following key issues: nursing roles in primary care and mental health; beliefs and attitudes associated with mental health care in primary care; perception of the factors that limit or encourage the care of mental disorders by nursing staff; training or availability to provide mental health care and socio-demographic data. The interviews were audio-taped and encoded to guarantee the confidentiality of each respondent

The first stage involved the observations, for which authorization from the health center authorities was requested. Subsequently, interviews were conducted with the nurses, for an average duration of two hours after permission had been granted. An "informed consent" form was given to each nurse, which included the project objectives, a request to audio-tape the interviews and ethical considerations (confidentiality of information, respect for respondents, risk-benefit evaluation, justice-equality, benefits of the research and conflict of interest). The research protocol was approved by the Ethics Committee of the Ramón de la Fuente Muñíz National Institute of Psychiatry.

\section{Information Analysis}

In the case of the field notes, information was transcribed into a field journal in order to subsequently reduce the data and select the information that would enable us to interpret the social phenomenon of interest on the basis of our observations and compare it with the information provided by the respondents.

The interviews were transcribed and coded, using the topics proposed in the interview guide as a starting point. We designed categories and subcategories to classify the information using rules of exhaustiveness and mutual exclusivity by segments representing a specific [22] idea in order to identify patterns between the narrative structures and visual representations obtained from the records during the observation. Table 1 shows the categories and subcategories constructed for analyzing the information.

Table 1: Analysis Categories

\begin{tabular}{|l|l|l|}
\hline & \multicolumn{1}{|c|}{ Category } & \multicolumn{1}{|c|}{ Subcategories } \\
\hline A & $\begin{array}{l}\text { Description of their perception of } \\
\text { the setting }\end{array}$ & Health center and nursing area \\
\hline B & $\begin{array}{l}\text { Description of nursing functions } \\
\text { in primary care }\end{array}$ & $\begin{array}{l}\text { Activities inside and outside } \\
\text { the unit }\end{array}$ \\
\hline C & $\begin{array}{l}\text { Mental health care activities in } \\
\text { primary care }\end{array}$ & $\begin{array}{l}\text { Nursing roles, functions of } \\
\text { mental health service, training } \\
\text { and availability }\end{array}$ \\
\hline D & $\begin{array}{l}\text { Beliefs, attitudes and knowledge } \\
\text { of mental health }\end{array}$ & $\begin{array}{l}\text { Definition of concept of mental } \\
\text { health, mental disorder, } \\
\text { experiences and knowledge }\end{array}$ \\
\hline E & $\begin{array}{l}\text { Factors that help or hinder } \\
\text { mental health care }\end{array}$ & $\begin{array}{l}\text { Factors in the area of nursing } \\
\text { and general factors regarding } \\
\text { the primary care center. }\end{array}$ \\
\hline F & Sociodemographic data & $\begin{array}{l}\text { Age, education, position, } \\
\text { seniority and characteristics }\end{array}$ \\
\hline
\end{tabular}




\section{Results}

Of the six nurses interviewed, half have completed technical studies, two hold university degrees, and one also has a specialty in the area of health in addition to her degree. The respondents with higher studies are younger and less experienced (Table 2).

\section{Setting}

The respondents all described the health center as a primary care facility focusing mainly on health prevention and promotion and classified as a T3, meaning that it is equipped with all the services for general consultation, laboratory, $\mathrm{x}$-rays and programs to facilitate compliance with quality health care standards. The main program is universal vaccination. The center also offers elderly care, family planning and cancer prevention programs.

Carina says that they are not allowed to deny care when requested because it is a public center. However, treating people from other areas or localities outside the unit zone creates a work overload. Brenda believes that most of those who come to the center are part of the floating population, since they continually encounter delays in their vaccination schemes. In this respect, Carina says that the most difficult population to treat are teenagers, including users with addiction problems, because on the one hand, they need more counseling and on the other, they fail to return because they do not wish to be scolded by the nurses.
However, Ana disagrees on this point; she says that the patients she treats in conjunction with the doctor at the surgery come in regularly. Some patients have routine check-ups in general practice, although she says that this is due to the GP's monitoring and interest in each of the users, a key factor in preventing patients from becoming part of the floating population.

As for the facilities, some of the respondents report that the areas are small, insufficient and poorly distributed, especially the surgery, located near the parking lot, which they find impractical for everyday activities. However, Daniela and Elena think that the health center has sufficiently large, well-integrated areas for the services provided by a primary care unit.

In the case of the nursing areas, most of them are shared. For example, for general consultations, space is occupied by the doctor with whom they work and nursing staff are sometimes forced to take notes on the examining table or wherever there is room. They also use a surgery for taking vital signs and somatometry because there is no designated area for performing nursing functions. A similar situation occurs in the nursing head office, which, despite having a specific cubicle for the nursing director and supervisors, is insufficient, as it is designed for use by one person. It was observed that much of the space was occupied by the equipment and sterilizing center known as CEYE, the cold network comprising industrial refrigerators, several desks, file cabinets, bandage and dressing trolleys and two staff restrooms.

Table 2: Sociodemographic Data

\begin{tabular}{|c|c|c|c|c|c|}
\hline Respondent & Age & $\begin{array}{l}\text { Educational } \\
\text { Attainment }\end{array}$ & Position & Seniority & Characteristics \\
\hline Ana & 43 years & Technician & General practice nurse & 21 years & $\begin{array}{l}\text { She regards herself as a kind, patient person, } \\
\text { who treats patients kindly. She enjoys talking } \\
\text { to them, give them their reports and explaining } \\
\text { about their care. }\end{array}$ \\
\hline Brenda & 32 years & Nursing degree & Nursing supervisor & 6 years & $\begin{array}{l}\text { She thinks she is not an unpleasant boss, but is } \\
\text { not permissive. She takes the staff's needs into } \\
\text { account and believes that the most difficult or } \\
\text { time-consuming part is resolving spontaneous } \\
\text { conflicts. }\end{array}$ \\
\hline Carina & 45 years & Technician & Chief Nursing Officer & 22 years & $\begin{array}{l}\text { As a nursing officer, she does not want to stop } \\
\text { having contact with the patients and thinks } \\
\text { that the best way of soothing tension is by } \\
\text { calming them down by listening and talking } \\
\text { to them. In her discourse, she emphasizes her } \\
\text { commitment and leadership in dealing with } \\
\text { the organization of the area. }\end{array}$ \\
\hline Daniela & 34 years & Nursing degree & Immunizations nurse & 4 years & $\begin{array}{l}\text { Her priority is counselling, which sometimes } \\
\text { takes time but she says that she needs this } \\
\text { space to gain the patients' confidence. }\end{array}$ \\
\hline Elena & 67 years & Technician & General practice nurse & 47 years & $\begin{array}{l}\text { She says she likes to arrive early, finish on time } \\
\text { and does not like to be distracted by other } \\
\text { things. In her discourse, she shows her love for } \\
\text { the profession. }\end{array}$ \\
\hline Fabiola & 38 years & $\begin{array}{l}\text { Nursing degree } \\
\text { (specialty) }\end{array}$ & Quality Management & 11 years & $\begin{array}{l}\text { For her the most important thing is attitude, } \\
\text { both hers and that of the staff that work there. } \\
\text { She says she must use coercion. Things do } \\
\text { not work under pressure but she can't be too } \\
\text { lenient either. }\end{array}$ \\
\hline
\end{tabular}


According to the respondents, the nursing team is composed of 23 nurses including the head and two supervisors, the remainder being clinical and district nurses, organized into an annual roster although there is also a daily roster for covering services in the event of absences, days off or sick leave. They believe that if they only had the core staff, they would be unable to cover all the tasks assigned. They are supported by nursing interns who are also included in the roster and according to Fabiola; human resources are the unit's most valuable asset.

The nurses said that the main activities undertaken at the health center are related to clinical care. In the surgeries, they take vital signs, "somatometry", check the vaccination booklets, give vaccinations and provide support for applying dressings or medical procedures. They also are responsible for providing information on the programs offered by the center. They agree that giving information and administrative functions (organizing and delivering records, collecting patients' data, and filling in weekly reports) are the most time-consuming activities. As a result of these multiple activities, they think they are sometimes overworked or lack the time to finish everything they have planned.

As for material resources, they agree that it is common not to have a minimum amount of materials required to perform their daily activities (gloves, flow sheets, prescriptions, vaccines, etc.) which prevents them from providing proper care and elicits numerous complaints from users.

District nurses are also responsible for other functions, which they usually perform outside the health center. Each nurse is assigned various districts, where she must take a census of all children under the age of eight in order to update the vaccination schemes, schedule home visits and invite residents to visit the health center. She must also compile a list of pregnant women. Nurses are supposed to cover approximately 30 visits a day, but this is difficult to achieve for a several number of reasons, including the time it takes to reach each home, the time spent there and the inaccessibility of certain areas.

\section{Mental health care activities in primary care}

It is important to note that none of the respondents "formally" performs mental health care activities. However, Ana said that intuitively and by talking to patients, they are able to recognize emotional disorders, data on violence or situations which they consider require a specialist. When the problem is very obvious, they refer patients to a psychologist. However, they are often unaware of the treatment available in mental health service and/ or have little contact with the specialists in that department.

They also said that although nursing staff do not offer any specific mental health programs, they often provide some form of "counseling". However, they feel they lack the necessary skills to engage in mental health care-related activities and are worried that despite their good intentions, they may do more harm than good. They believe that they have suffered from this lack of mental health care training ever since they began their nursing training.

\section{Beliefs, attitudes and knowledge of mental health}

Mental Health and the Concept of Mental Disorders: The respondents agreed on certain aspects of the concept of mental health. They regard it as the mental and psychological well-being of an individual, who must maintain a balance that allows him to function in various areas of his life such as social, family and personal aspects, which are mainly associated with handling emotions. However, each respondent has a particular definition of the term and some of them agree that the family is an important element.

Conversely, some people describe a mental disorder as a disorder caused by a condition that creates chaos; thus a person may appear well although he or she actually has a disorder. They even mentioned somatizations as being subsumed under disorders.

Knowledge: Most respondents stated that the main mental disorders they know are depression and anxiety; a few mentioned others such as schizophrenia and bipolar disorder. However, they admitted their lack of knowledge about mental health and said they are barely able to identify mental disorders or distinguish between them. Accordingly, the majority expressed an interest in training, since it could be useful in their personal and professional lives. Over time, they have acquired skills to identify and learn to convey calm. They think that the way they treat people who are distressed is crucial, so the best way to reduce patients' stress is to take time to listen to them. However, they are not used to dealing with this type of population and do not have enough time to treat these patients.

Experiences /Positive and Negative Beliefs: Respondents mentioned the persistence of certain misconceptions or myths about people diagnosed with a mental disorder because they are thought to be aggressive. These patients elicit negative reactions from other users, particularly rejection and the nurses have also felt frightened because of their lack of knowledge of particular disorders. They therefore believe that identifying or diagnosing these diseases requires specialized assessment.

Regarding the image they have of a person with a mental disorder, the majorities agree that they look unkempt and unstable and are emotionally labile; they feel frightened and sometimes engage in violent behavior, except for Ana. They therefore assume that social prejudice may be one reason why a person allows a mental disorder to go untreated and worsen, in addition to cases that go untreated due to lack of medication. Table 3 exemplifies some of these types of discourse.

Factors that help or hinder mental health care: The nurses attributed the lack of mental health care to the fact that it has not been given enough importance, it is a neglected area because greater emphasis is placed on physical problems, meaning that programs focusing on mental health have not been designed.

However, they are fully aware that during consultation, patients need to be listened to, in addition to having their physical ailments attended to and sometimes providing this kind of "listening" becomes part of nurses' functions, despite the fact 
Table 3: ( Examples of the nurses' discourse ) Beliefs, attitudes and knowledge towards mental health

\begin{tabular}{|c|c|}
\hline $\begin{array}{l}\text { Concept of } \\
\text { mental health }\end{array}$ & $\begin{array}{l}\text { “... It just involves handling emotions ..." } \\
\text { Mental health, I think ... it should take place in three } \\
\text { spheres, psychological, social and biological. }\end{array}$ \\
\hline $\begin{array}{l}\text { Concept of } \\
\text { mental disorder }\end{array}$ & $\begin{array}{l}\text { "... I think that a mental disorder is an accumulation } \\
\text { of things..." } \\
\text { "... I think that it is because of the problems there } \\
\text { are..." }\end{array}$ \\
\hline $\begin{array}{l}\text { Experiences/ } \\
\text { Positive Beliefs }\end{array}$ & $\begin{array}{l}\text {... Over time you learn to identify things and try to } \\
\text { calm them and not give in to them ... and have a little } \\
\text { more tact ... }\end{array}$ \\
\hline $\begin{array}{l}\text { Experiences/ } \\
\text { Negative Beliefs }\end{array}$ & $\begin{array}{l}\text {... It's crazy, there are people who are scared, they } \\
\text { react with fear and there is some rejection too... } \\
\text {... Before knowing what type of disorder it is ... we feel } \\
\text { is as very aggressive or very demanding person... }\end{array}$ \\
\hline Knowledge & $\begin{array}{l}\text { "Once, sometimes they taught us a subject about } \\
\text { psychology or psychiatry, albeit very generally..." }\end{array}$ \\
\hline
\end{tabular}

that they have no specialized knowledge. They believe that in order to incorporate actions into mental health, it is essential to provide a work plan on the subject, which could include nursing staff because they agree these needs must be met by undertaking health promotion and prevention activities, and moreover that there are factors that enhance treatment, such as being the patient's first contact.

Lastly, they agree that campaigns should be jointly undertaken to sensitize the population. Activities should be carried out to disseminate knowledge for both health personnel and users and actions should be performed to achieve more detections and referrals to the area of mental health.

As one can see, these results illustrate the various situations that should be considered prior to the incorporation of actions oriented towards mental health. Although nursing staff may have the tools to practice "active listening" with the knowledge required to detect the main symptoms of a disorder, major changes are required in addition to training. Measures must be taken to achieve their professionalization while policies and programs must be designed to standardize both their functions and the actions to be carried out in primary care settings.

\section{Discussion}

This research focuses on pointing out some of the difficulties nurses face in incorporating actions to treat mental health disorders. In the first instance, it is important to mention that public primary care centers in Mexico suffer from a lack of resources, because despite having 12,000 basic units, only $30 \%$ operate optimally [23]. Likewise, the number of psychologists, psychiatrists and mental health professionals is insufficient and material resources are limited, all of which are key factors limiting this level of care. This may be the reason why nurses agreed that there is no proper structure to add a new area such as mental health service.

In contrast with mental health, the study revealed the lack of knowledge; each nurse has its own definition, so they cannot identify symptoms of mental diseases as standard practice. Additionally, it was found that there is no standardization in nurse's professional training; some said that they have had a particular mental health issue during their studies, but in general, none of them had received solid training in this area. Nonetheless, some of the nurses informally performed functions such as "active listening and relieving patients' feelings," they believe that this empirical knowledge is the result of years of working in this field.

Conversely, the respondents' views reflect the persistence of certain stigmatizing attitudes, associated with entrenched cultural beliefs and misinformation. As mentioned earlier, one of the main obstacles to care is lack of training or knowledge, which emerged in the different ways mental health and disorders are defined. This is a matter of concern since lack of knowledge is directly responsible for negative experiences during the care of this type of disorders [24].

They acknowledge that nurses would be able to provide preventive actions and mental health care if they had the necessary or at least minimal elements, such as training and specific programs. However, the scarcity of "formal" work in the field of mental health is reflected in the fact that nurses' activities primarily revolve around the Universal Vaccination Program, although it is interesting that the respondents, despite repeatedly mentioning their work overload, take the time during their activities to listen to users, since they realize that this is a permanent need. Nevertheless, given the informal nature of these activities, it is impossible to know whether they benefit users.

In relation to the above, it is worth noting that the nurses do not deny the existence of care plans for this type of disorders to be delivered by nursing professionals, since a specialty does in fact exist. Unfortunately, in Mexico, mental health specialists are concentrated at the tertiary level and the main obstacle they face is the lack of recognition of their activities. Accordingly, Dawes [25] mentions the importance of breaking paradigms and involving the health team in interventions oriented towards psychiatry and establishing a clear identity for nursing professionals. It would be advisable to give them greater autonomy and empowerments while implementing organizational changes that encourage independent actions.

This contrasts with the role performed by nurses at the primary care level in other countries, as happens in Canada and Australia, where they are responsible for diagnosis, treatment and rehabilitation as part of a system of continuous collaboration with the rest of the health team.

The information provided by the respondent's shows that nursing staff serve as a bridge between the health system and 
the community. Accordingly, in collaboration with other health professionals, they could deliver mental health actions that would permit the early detection of mental disorders, the promotion of healthier lifestyles and the continuous monitoring of patients in the community.

In conclusion, this research, despite being unable to provide concrete solutions to a problem, shows that nurses can be regarded as an area of opportunity. Secondly, it analyzes the difficulties involved in incorporating mental health-based actions into their functions, while realizing this would only be the first step of a long journey.

One of the study's limitations is that the research was only conducted at one primary care center. In order to have a broader view of this issue, one would have to explore other units in order to obtain a broader view of the nursing profession's views on the issue of mental disorders.

Lastly, the authors recommend that future studies continue to explore nurses' role in primary care in depth, mainly because of their emotional skills, which could prove useful in delivering mental health care. Attempts should also be made to empower the profession, because without sufficient autonomy, new policies will continue to be segregated. In other words, attempts must be made to strengthen their work and incorporation into primary care by increasing the emphasis on the field of mental health since their functions are apparently devalued.

The promotion of scientific evidence is essential, since this is the main tool for publicizing the impact of both a disorder and the care provided. Statistical data require further updating since outdated information places us at risk of repeating mistakes. There is therefore a need to continue creating new knowledge in order to provide standardized care and improve the quality of care provided.

\section{Acknowledgement}

The authors wish to express their gratitude to the Secretaría de Saluddel Distrito Federal and especially to the persons who shared their experiences in interviews and made this study possible.

\section{Declarations}

\section{Conflict of Interest}

The authors declare that no conflicts of interest exist.

\section{Ethical Approval}

This research project was approved by the Research Ethics Committee of the Ramón de la Fuente National Institute of Psychiatry. . It was determined that the project presented no risks and that informed consent could thus be obtained verbally. Each potential interviewee was provided with a "verbal consent form," which guaranteed the confidentiality of any information provided (using pseudonyms).

\section{References}

1. Serrano M, Torres TM, Ávalos G. Concepciones culturales en torno a la salud y la enfermedad en población de adultos de Jalisco, México. Rev Salud Pública y Nutrición. 2009;10:3
2. Ángeles Constantino MI, González GN. Apuntes para repensar la "teoría de la transición epidemiológica" y su importancia para el diseño de políticas públicas. Espacios Públicos. 2009;12(25):151-162.

3. Vos T, Barber RM, Bell B, Bertozzi-Villa A, Biryukov S, Bolliger I, et al. Global, regional, and national incidence, prevalence, and years lived with disability for 301 acute and chronic diseases and injuries in 188 countries, 1990-2013: a systematic analysis for the Global Burden of Disease Study 2013. Lancet. 2015;386(9995):743-800. doi: 10.1016/ S0140-6736(15)60692-4.

4. Berenzon S, Lara MA, Robles R, Medina-Mora ME. [Depression: state of the art and the need for public policy and action plans in Mexico]. Salud Publica Mex. 2013;55(1):74-80.

5. Vargas TBE, Villamil V. La salud mental y la atención primaria en México. Experiencias de un modelo de atención colaborativa. Rev Salud Mental. 2016;39(1):3-9.

6. Gureje O, Von Korff M, Kola L, Demyttenaere K, He Y, Posada-Villa J, et al. The relation between multiple pains and mental disorders: results from the World Mental Health Surveys. Pain. 2008;135(1-2):82-91.

7. Scott KM, Von Korff M, Alonso J, Angermeyer MC, Bromet E, Fayyad $J$, et al. Mental-physical co-morbidity and its relationship with disability: results from the World Mental Health Surveys. Psychol Med. 2009;39(1):33-43. doi: 10.1017/S0033291708003188.

8. Kohn R, Levav I, De Almeida JM, Vicente B, Andrade L, CaraveoAnduaga JJ, et al. Mental disorders in Latin America and the Caribbean: a public health priority. Pan American Journal of Public Health. 2005;18(4-5):229-240.

9. Kroenke K, Spitzer RL, Williams JB, Monahan PO, Löwe B. Anxiety disorders in primary care: prevalence, impairment, comorbidity, and detection. Ann Intern Med. 2007;146(5):317-25.

10. Federación Mundial para la Salud Mental [WFMH]. Salud Mental en la atención primaria: mejorando los tratamientos y promoviendo la salud mental. 2009

11.World Health Organization/ World Organization of Family Doctors [WONCA]. Integrating mental health into primary care: a global perspective, Singapore: WHO. 2008.

12. Colorado A. Estrategias de inversión y conversión del capital cultural y otros tipos de capital en la definición de las trayectorias escolares universitarias. El caso de los estudiantes de Medicina e Ingeniería Civil de la Universidad Veracruzana. Master's thesis in sociology. Mexico: Universidad Autónoma Metropolitana. 2008.

13. Weight EJ, Kendal S. Staff attitudes towards inpatients with borderline personality disorder. Mental Health Practice. 2013;17(3):34-38.

14. Albuixech R. The reflection of the social stigma of the mental patient on their caregivers: The training as an alternative. Nure Investigación. 2004;10(1):1-9.

15. World Health Organization. Atlas: nurses in mental health. 2007.

16. Saxena S, Lora A, van Ommeren M, Barrett T, Morris J, Saraceno B. WHO's Assessment Instrument for Mental Health Systems: collecting essential information for policy and service delivery. Psychiatr Serv. 2007;58(6):816-21.

17. Medina-Mora ME, Borges G, Lara CM, Benjet C, Blanco JJ, Fleiz CB, et al. Prevalencia de trastornos mentales y uso de servicios: resultados de la encuesta nacional de epidemiología psiquiátrica en México. Rev. Salud Mental. 2003;26(4):1-16.

18. Berenzon SG, Saavedra SN, Medina-Mora ME, Aparicio VB, Galván RJ. Evaluación del sistema de salud mental en México: ¿hacia dónde encaminar la atención? Rev. Panam Salud Pública. 2013;33(4):252-8. 
19.Delgado J, Gutiérrez J. Métodos y Técnicas Cualitativas de Investigación en Ciencias Sociales. Editorial Síntesis. Madrid. 2003.

20. Taylor SJ, Bogdan R. Introducción a los métodos cualitativos de investigación. Paidos. 1986:20-109.

21. Anguera MT. La investigación cualitativa. Educar. 1986;10:23-50.

22. Secretaría de Salud. Programa Nacional de Salud. Por un México sano: construyendo alianzas para una mejor salud 2007-2012.

23. Dawes K. Solution based teaching methods in a problem based curriculum: the role of a mental health nurse in addressing the challenges of curriculum delivery in a regional medical school. International Journal of Mental Health Nursing. 2013;22(Suppl. 1):56.

24. Richards C, Rafferty L, Gibb A. The value of mental health nurses working in primary care mental health teams. Mental Health Practice. 2013;16(10):19-23.

25.Alarcón M. Modelo integrador de enfermería: una estrategia para la Atención Primaria a la Salud. Rev Enferm Inst Mex Seguro Soc. 2013;21(1):35-40. 